REVIEW ARTICLE

\title{
Opinions about the future of Clinical Trial in Turkey
}

\author{
Nüket Büken
}

\section{ABSTRACT}

Even though all the rights and obligations of all parties of clinical trial - the researching physician, the volunteering patient, the industry, research institutions- have been assured with ethico-legal regulations, there still exist many problems in the world of clinical research, and suggestions of solutions to the said problems.

As a medical ethicist who has been a permanent member of the Hacettepe University Ethical Committee since 2000, I have decided to write a short report that is a general look at the world of clinical research in Turkey. I wanted this report to be one that talks about some of the issues I believe are important about this subject, which include expectations and predictions on it.

All of the headlines in this report are without doubt, issues that can be researched and written about widely and with much more details. Especially the process of adjustment to the new regulation of the EU (No 536/2014 of The European Parliament), the condition of non-medicational/non interventional clinical research, transparency in clinical research and budget issues are to me controversial subjects that should be especially and primarily discussed.

Keywords: Clinical research, non-interventional clinical research, regulation

\section{INTRODUCTION}

Insanlar üzerindeki biyomedikal araştırmaların bir yandan tıptaki gelişmeleri hızlandırdığı, kanıta dayalı tıbbi bilgileri arttırdığı ve gelecek kuşaklar için yararlar sağladığı, ancak öte yandan kötüye kullanılmaları durumunda insanın saygınlığını, değerini tehlikeye atan eylemlere yol açabilecekleri açıktır. Yeni ve etkili ilaçlar geliştirmek için yapılan araştırmalar günümüzde son derece doğal karşılanmaktadır ve bu çalışmalar tüm toplumlarda ortak olan bazı iyi belirlenmiş bilimsel standartlara ve etik kurallara uygun olarak yürütülmektedir.

Ülkemiz de klinik araştırmalar açısından potansiyeli olan bir ülkedir; son 20-30 yılda kişi başı hekime müracaat sayısı 6 kat, yeni tedavi ve ilaçlara ulaşımın artması ile de ortalama yaşam süresi \% 25 artmıştır. Ülkemizin toplam klinik araştırmalar içindeki payı 2011 yılında \% 0,8 iken (çalışma sayısı 978), bu oran 2015 yılında \% 0,95 (çalışma sayısı 1.746) olmuştur. Dört yıllık dönemde (2011-2015) ülkelerin toplam klinik araştırmalar içindeki payı açısından sıralamada 36. Sıradan, 31. sıraya yükselmiştir, ancak bu yeterli görülmemektedir. Türkiye'nin de Güney Kore ve Çin gibi ilk 10'da yer alması beklenmektedir. Klinik araştırma dünyasına baktığımızda küresel ilaç yatırımları açısından "pharmerging" ülkeler - BRIC (BRIC: Brezilya, Rusya, Hindistan ve Çin)- olarak adlandırılan Brezilya, Rusya, Hindistan, Çin gibi ülkelerden daha geri oluşumuz, bu konudaki uygulamaları, güçlü/zayıf yönlerimizi, olanaklarımızı yeniden gözden geçirmek gereğini doğurmuştur.

\section{Ülkemizdeki Mevzuat}

Türkiye'de klinik araştırma süreci değerlendirildiğinde yasal olarak 1993 yılından beri klinik araştırmaların ilgili taraflarını bağlayıcı hükümlerin var olduğunu ve bu yasal sürecin, Avrupa Birliği'ne uyum sürecinde uluslararası etikolegal düzenlemelerle uyum içerisinde değişime uğradığını söyleyebiliriz. Avrupa Konseyi İnsan Hakları ve Biyotıp Sözleşmesi (Oviedo) [1], WMA - Dünya Tabipler Birliği Helsinki Bildirgesi, İnsanlar Üzerinde Araştırma ve Deneylerde Etik İlkeler veya Uluslararası Tıp Bilimleri Örgütü (Council for International Organizations of Medical Sciences - CIOMS) ve

Hacettepe University Bioethics Center, Department of Medical Ethics \& Medical History, Ankara, Turkey

Correspondence: Dr. Nüket Büken,

Hacettepe University Department of Medical Ethics \& Medical History, Ankara, Turkey

E-mail: nuketbuken@hotmail.com

Received: 15 March 2016, Accepted: 20 June 2016

Copyright @ JCEI / Journal of Clinical and Experimental Investigations 2016, All rights reserved 
insanlar üzerindeki araştırmalarda uluslararası etik kılavuzlar gibi belgeler bunlara örnektir.

İlaç ve Biyolojik Ürünlerin Klinik Araştırmaları Hakkında Yönetmelik [2]'in kapsamına bakıldığında; biyoyararlanım ve biyoeşdeğerlik çalışmaları dâhil, insanlar üzerinde yapılacak olan ilaç, tıbbi ve biyolojik ürünler ile bitkisel ürünlerin klinik araştırmalarını kapsamına aldığı görülür. Sorumlu araştırmacı da araştırma konusu ile ilgili dalda uzmanlık veya doktora eğitimini tamamlamış, araştırmanın yürütülmesinden sorumlu olan hekim veya diş hekimi olarak tanımlanır. İlgili Yönetmeliğin 11. Madde'si klinik araştırma yapılacak yerler ile ilgili olarak; "klinik araştırmalar, üzerinde araştırma yapılacak kimselerin emniyetini sağlamaya ve araştırmanın sağlıklı bir şekilde yürütülebilmesine, takibine ve gereğinde acil müdahale yapılabilmesine elverişli ve araştırmanın vasfına uygun personel, teçhizat ve laboratuvar imkânlarına sahip olan, tercihen klinik araştırma yapmak üzere tasarlanmış yerlerde yapılabilir" der.

Gözlemsel tıbbi cihaz çalışmaları da dâhil tüm tıbbi cihaz klinik araştırmaları Tıbbi Cihaz Klinik Araştırmaları Yönetmeliği [3]'ne uygun olarak yürütülür. IIlgili Yönetmelik, "Illaç ve Biyolojik Ürünlerin Klinik Araştırmaları Hakkında Yönetmelikte yapısı, çalışma usûl ve esasları belirtilen ve Kurumdan onay almış Klinik Araştırma Etik Kurulları, bu Yönetmelik hükümlerine tabi tüm tıbbi cihaz klinik araştırmalarını da değerlendirir; tıbbi cihaz klinik araştırmalarını değerlendirmek üzere ayrıca bir etik kurul teşkil edilmez" der.

İlgili Yönetmeliklere uygun olarak oluşturulmuş etik kurullar faaliyetlerine devam etmektedirler. Sık olarak değişen yasal mevzuat nedeniyle bazı dönemlerde süreçte aksamalar yaşanmış olsa da son 30 yılda ülkemizde Klinik Araştırma Etik Kurulları açısından belli bir gelenek ve deneyim oluştuğunu söylemek mümkündür.

\section{Girişimsel Olmayan Klinik Araştırmalar ve Bu Araştırmalar ile ilgili Etik Kurullar}

İlaç ve Biyolojik Ürünlerin Klinik Araştırmaları Hakkında Yönetmelik ile Tıbbi Cihaz Klinik Araştırmaları Yönetmeliği'nin kapsamı dışında kalan, Bakanlık/ Illaç ve Tıbbi Cihaz Kurumu onayı gerektirmeyen ancak etik kurul değerlendirmesi yapılması önemli olan klinik araştırma alanları da mevcuttur.

Tüm gözlemsel çalışmalar, anket çalışmaları, dosya ve görüntü kayıtları gibi retrospektif arşiv taramaları, kan idrar, doku, radyolojik görüntü gibi biyokimya, mikrobiyoloji, patoloji, ve radyoloji koleksiyon materyalleriyle veya rutin muayene, tetkik, tahlil ve tedavi işlemleri sırasında elde edilmiş materyallerle yapılacak araştırmalar ile hücre veya doku kültürü çalışmaları; gen tedavisi klinik araştırmaları dışında kalan ve tanımlamaya yönelik olan genetik materyalle yapılacak çalışmalar, hemşirelik faaliyetlerinin sınırları içerisinde yapılacak araştırmalar, gıda katkı maddeleriyle yapılacak diyet çalışmaları, egzersiz gibi vücut fizyolojisi ile ilgili araştırmalar, antropometrik ölçümlere dayalı yapılan çalışmalar ve yaşam alışkanlıklarının değerlendirilmesi araştırmaları gibi insana bir hekimin doğrudan müdahalesini gerektirmeden yapılacak tüm araştırmaların da etik ilke ve kurallar doğrultusunda yapılabilirliğinin kurumsal denetimine gereksinim bulunmaktadır.

Bu tür çalışmalar için bazı üniversiteler kendi etik kurullarını oluşturmuşlar ve Yönergelerini üniversite senatolarından da geçirerek ilgili konudaki boşluğu doldurmaya çalışmışlardır. Hacettepe Üniversitesinde de bu bağlamda Hacettepe Üniversitesi Senatosunun 11. 01. 2012 tarih ve 2012-58 sayılı kararı ile Girişimsel Olmayan (Non interventional) Klinik Araştırmalar Etik Kurulu oluşturulmuştur. Bu kurul son 4 yılda 4000'e yakın araştırma başvurusunu değerlendirmiştir; bu araştırmalar, TÜBITAK ve HÜ BAB tarafından desteklenen çalışmalar olduğu gibi destekleyicisi olmayan bireysel araştırma başvuruları ya da uzmanlık/doktora tez çalışmalarıdır. 2012 yılından önce de bu tür araştırmaları değerlendiren ancak farklı bir adla çalışan (Senato Etik Kurulu) bir kurumsal değerlendirme kurulu vardı. Hacettepe Üniversitesi Sağlık Bilimleri Enstitüsünde yapılan tüm Yüksek lisans/doktora tez çalışmalarının ve uzmanlık tezlerinin etik kurul onayı alması zorunluluğu bulunmaktadır.

Klinik Araştırmalar ile ilgili yönetmelikler (İlaç ve Biyolojik Ürünlerin Klinik Araştırmaları Hakkında Yönetmelik, Tıbbi Cihaz Klinik Araştırmaları Yönetmeliği) sorumlu araştırmacı olarak "hekim veya diş hekimi"ni tanımladığı için, sağlık bilimlerinin diğer alanlarında (Hemşirelik, 
Beslenme ve Diyetetik, Ergoterapi, Fizyoterapi ve Rehabilitasyon, Odyoloji, Spor Bilimleri alanlarında) yapılan tezlerde veya bireysel araştırmalarda, ilgili alan uzmanlarının sorumlu araştırmacı olabilmesi konusunda (Ph D/ Doktorası olan) var olan sıkıntılar bu tür kurumsal değerlendirme kurulları yoluyla aşılmaya çalışılmıştır.

Ancak Sağlık Bakanlığı tarafından hazırlanan ve değerlendirilmek üzere ilgili kişi ve kurumlara gönderilen İlaç Dışı Klinik Araştırmalar Hakkında Yönetmelik Taslağı, söz konusu bu araştırmaları da Bakanlık değerlendirme süreçlerine katmayı öngörmektedir. Taslak Yönetmeliğe göre sorumlu araştırmacı bu çalışmalar için de, "hekim veya diş hekimi" olarak tanımlanmıştır (madde 4) ve Klinik Araştırma Etik Kurullarının bu yönetmelik kapsamındaki çalışmaları da yani İlaç Dışı Klinik Araştırmaları da değerlendireceği söylenmiştir. Bu taslak yönetmeliğin kapsamindaki araştırma konularını değerlendirmek üzere başka kurum ve kuruluşlarca etik kurul veya etik kurul fonksiyonlarını icra edecek başka bir kurul oluşturulamayacağı ifade edilmiştir (Madde 21). $\mathrm{Bu}$ yönetmelik taslağı bu şekli ile yürürlüğe girdiği takdirde, bilim doktoralı araştııcılar, katılımcısı insan olan araştırmalarda sorumlu araştırmacı olamayacaklardır. $\mathrm{Bu}$ durumun yaratacağı karışıklık bilindiği gibi daha önce de yaşanmış, sağlık bilimleri alanlarında yapılan tezlerde danışmanlar, sorumlu araştırmacı olamamışlardı. Zaten bu sorunu aşmak üzere, süreç içerisinde, kurumsal etik kurullar/girişimsel olmayan araştırma etik kurulları yapılandırılmıştı. Umarı ki aynı hata yeniden tekrarlanmaz ve doktora derecesine sahip araştırmacıların sorumlu araştırmacı olması önünde yeni engeller oluşturulmaz.

İlgili Avrupa Komisyonu Direktifleri ve Uygulanabilme Koşulları

\section{1/20/EC Direktifi ile 2014/536/EC Direktifinin Karşılaştırması ve Bu Açıdan Yapılması Öngörülen Değişiklikler}

Halen geçerliliğini koruyan ve ulusal düzenlemelerimize kaynak oluşturan yönerge, Avrupa Komisyonu Klinik Araştırmalar Yönergesi/Direktifi (2001/20/EC)'dir. Avrupa Birliği $(A B)$ ülkelerinde, tıbbi ürünlerin klinik araştırmalarda kullanılmasını düzenlemektedir. Yönerge, üye ülkelerden birinde yürütülen çok merkezli klinik araştırmalarda, inceleme sürecinde yer alan etik kurul sayısına bakılmaksızın, o üye ülkede, projenin etik kurul incelemesinden geçirilerek, etik kurul görüşünün alınmasını düzenleyen bir prosedür olması gerekliliğini vurgular. Yönerge, birden çok üye ülkede eş zamanlı olarak yürütülen çok merkezli araştırmalarda, araştırmalara katılan üye ülke etik kurullarının görüşünün alınmış olmasını şart koşar [4]

16 Nisan 2014 tarihinde yayınlanan yönetmelik 2014/536/EC (Regulation (AB) No 536/2014 of the European Parliament and of the Council of 16 April 2014 on clinical trials on medicinal products for human use, and repealing Directive 2001/20/EC (Text with EEA relevance) Mayis 2016 tarihinden sonra uygulanmaya başlayacaktır. Bu regülasyonun temel özellikleri şunlardır [5];

- Tek bir giriş noktası üzerinden bir başvuru prosedürü, $A B$ portalı tanımlanmıştır,

- Belgelerin bir tek set halinde hazırlanıp, sunulması öngörülmüştür; klinik araştırmalarda, başvuruların değerlendirilmesi için bir uyumlaştırımış prosedür tanımlanmıştır. İlk bölümde ilgili tüm üye devletlerin ikinci bölümde ise her üye devletin kendisinin değerlendirme yapabileceği şekilde düzenleme yapılmıştır. Burada her iki aşamada da etik kurulun yer alıp almayacağı tartışmalıdır. Rapor eden üye devletin inisiyatifine bırakılması da söz konusudur.

- Klinik deneme uygulamasının değerlendirilmesi için kesin tarihler belirlenmiştir.

- $\quad$ İlgili üye devletlerin ulusal hukuku ile değil, $A B$ regülasyonu ile belirlenen toplam süreler içinde etik kurullarının uygun değerlendirme prosedürüne katılımının sağlanması istenmiştir.

- Klinik deneyler ve bunların sonuçlarının şeffaflığı önemsenmiş ve bununla ilgili uygulamalar tanımlanmıştır.

- Üye devletlerin, üçüncü dünya ülkelerinde klinik denemelerin kurallara uygun ve düzgün yürümesini sağlamak konusunda sorumluluk alması istenmiştir. 
- $\quad A B$ dışında yapılan ancak $A B$ içinde bir klinik deneme uygulamasında refere edilen klinik araştırmalar, en azından AB'de geçerli eşdeğer düzenleyici gereksinimlere uymak zorunda bırakılmıştır.

Bu Regülasyon ile $A B$ ülkelerinde araştırma tek dosya üzerinden ilerleyecektir. Etik Kurul başvurusu ve onay sonrası değişiklik bildirimleri için de tek dosya üzerinden ilerleyecek bir süreç öngörülmektedir. İlgili Regülasyonda klinik araştırma tanımlarının yeniden yapılmış olması, ilgili kavramların doğru tanımlanması/anlaşılması açısından önemlidir; Klinik Çalışma- Clinical Study, Klinik DenemeClinical Trial, Düşük Müdahaleli Klinik DenemeLow Intervention Clinical Trial tanımları yapılmıştır.

2014/536/EC Direktifine göre Bilgilendirilmiş Gönüllü Olur Formu (BGOF) ülkelere göre değişebilir; bu durum kanımızca yürütülen çok merkezli/çok uluslu çalışmalarda gönüllünün hak/esenlik ve güvenliğinin korunmasında risk oluşturabilir. Ayrıca UNESCO bildirgelerinde sık sık vurgulanan kuzey/güney, gelişmiş/az gelişmiş ülkeler arası güç ve erk kullanma sorunlarına da yol açabilir. BGOF uluslararası araştırmalarda standart olmalıdır çünkü bilgilenme ve bilgiye dayalı karar verme süreci, gönüllünün araştırma sürecinde en özenle korunması gereken hakkıdır ve araştırmaların bu olmazsa olmazları uluslararası belgelerle güvence altına alınmış olup, bunun uygulamaya yansıması da "standardize form" "standardize bilgilenme süreci” şeklinde olmalıdır.

İlgili direktifle yetim ilaçlar ile ilgili klinik araştırma teşviki gelmektedir ki bu teşvikler zaten başlamıştır. Nadir hastalıklar üzerine yapılan araştırmaları destekleyen Avrupa Komisyonu programı E-Rare-3 (Nadir Hastalık Araştırmaları), 2016 başlığı "Clinical research for new therapeutic uses of already existing molecules (repurposing) in rare diseases" olarak açılmıştır [6]. Klinik/klinik öncesi çalışmaların, yeni nadir hastalık tedavilerinin keşfinde ve/ veya hali hazırda var olan kanıtlanmış nadir hastalık tedavilerinin yeniden konumlandırılmasına yönelik çağrıya 17 ülkeden 25 enstitü dahil olmuştur ve yetim ilaçlarla ilgili klinik araştırma başvuruları artış göstermiştir. Ülkemiz zaten hastalık yükü, akraba evlilikleri ve farklı etnik yapılanmalar nedeniyle nadir hastalıkların görülme sıklığı açısından önemli bir ülkedir.

\section{Yetişmiş Nitelikli İnsan gücü Açığı}

Klinik çalışmalarda istihdam edilecek personelin sayısı ve niteliği önemlidir, bir klinik araştırmanın en önemli kısmı olan hasta ile görüşme, muayene ve kaynak dokümanlara not konulması aslında çalışmanın en az zaman alan kısmıdır. Çalışma ile ilgili yazışmaların takibi, etik kurul ile yapılan yazışmaların takibi, ilaç sayımları, hasta örneklerinin alınıp gönderilmesi, sonuçların takibi gibi yardımcı personellerin yapabileceği aktiviteler daha fazla zaman almaktadır. Bu nedenle klinik çalışmalarda kullanılmak üzere yardımcı personel istihdamı ve bu personelin niteliği, eğitimi önemlidir. Yakın gelecekte araştırma hemşiresi, eczacısı, teknisyen gereksinimi daha da görünür hale gelecektir.

\section{Klinik Araştırmalarda Şeffafık}

2014/536/EC Direktifine göre klinik deneme başlamadan, ücretsiz ve kamuya açık veri tabanına (ICTRP- International Clinical Trials Registry Platform) kayıt yapılacaktır. $A B$ veri tabanındaki tüm bilgiler (ticari gizli bilgiler, kişisel veriler içeren bilgiler hariç) prensipte kamuya açık olacaktır. Halen ClinicalTrials.gov [7] veri tabanında 170 'den fazla ülkede yürütülen yaklaşık 200.000'den fazla klinik deneme izlenebilmektedir. Vatandaşları ve araştırmacıları bilgilendirmek amacıyla ülkemizde yürürlükte olan ilgili mevzuat gereğince de gönüllü insanlar üzerinde yürütülen akademik veya destekleyicisi olan klinik araştırmaların (ilaç, tıbbi cihaz) kayıtlarının tutulduğu veri tabanı http://kap.titck.gov.tr [8] linki ile erişime açılmıştır.

Tüm klinik araştırmaların hedef, amaç ve beklenen süreleri ile sadece olumlu sonuçları değil beklenen tüm sonuçlarının kamuya açık bir veri tabanına kaydedilmesi önemlidir. Verilerin kamuya açık hale getirilmesinin nedeni şeffafığın artırıması ve olumsuz, zararlı veya bir sonuca varmayan etkileri hekimler, hastalar ve denetimcilerden saklamayı hedefleyen sözde "seçici raporlama" ve "taraflı yayın"ların önüne geçmektir. Kuşkusuz bu durumun olası ekonomik sonuçları da bulunmaktadır. Önemli ilaç çalışmalarının tümünün kayıt altına alınmaması 
çok daha pahalı tıbbi ürünler, aşılar ve aygıtların üretilmesine yol açabilir. Bu uygulama tüm ilaç çalışmalarına ilişkin şeffaflığın sağlanması için yasal düzenleme önerisini getirirken, diğer taraftan çalışma başlatılığında kayda girilmeyen klinik denemelerin sonuçlarının dergi editörleri tarafından yayınlanmaması gerektiğini öne süren görüşlere de haklılık zemini yaratmaktadır.

\section{Araştırma Bütçesi ile ilgili Konuşulmayan Konular}

Araştırma etik kurulları, klinik araştırmayı belirleyen temel ilişkiler konusundaki düşünceler nedeniyle kurulmuş olmalarına karşın, ilgili öteki taraflar da artık, özellikle de mali konularda önemli, bazen de algılanamayan roller üstlenmişlerdir. Bu taraflar ve bunların çıkarları, ortaya ne ölçüde çıkarlarsa çıksınlar ve etik kurullar tarafından çeşitli zamanlarda göz önünde bulundurulsun ya da bulundurulmasın, herhangi bir belirli araştırmada doğrudan ya da dolaylı olarak çatışabilir ya da tersine hiç bir araya gelmeyebilir. Bunları birbirine bağlayan mali konular açık olabilir ya da olmayabilir. Bu tartışma, klinik araştırmalardaki temel ilişkiler konusunda görüş yürütülerek başlar ve diğer taraflar da katıldığında mali soruları düşündürür [9].

Sağlıklı bir gönüllü ile araştırmacının ilişkisi göz önüne alındığında genellikle ortaya çıkan mali konu şudur: gönüllünün araştırma projesine katıımı için "uygun" ya da "makul pay" nedir? $\mathrm{Ne}$ olmalıdır? İster sağlıklı isterse de hasta gönüllü olsun, araştırmada yer alacak kişinin; iş/güç kaybı, ulaşım, konaklama ücreti (il dışından gelecek ise), yemek masraflarının araştırma bütçesinden karşılanması gerekmektedir. Katııım sağlanan etkinliğin süresi, gösterilen çaba, öngörülen risk ve rahatsızlık yaratma durumu göz önüne alınması gereken konulardır. Rahatsızlık verme durumu gündeme geldiğinde, etik kurul üyeleri tarafından ortaya konulan bireysel düşünceleri gözlemlemek de ilginç olabilmektedir. Etik kurul üyelerinin bireysel düşünce ve değerlerinin etik kurul kararlarına etkisi ne olacaktır? Üyelerin yaşı, deneyimleri bazen cinsiyetleri ve kuşkusuz mali durumları, tutumlarını belirlemede etkileme olasılığı bulunan etkenlerdir [9].
Illgili literatür incelendiğinde konuyla ilgili olarak ilk başta "adil bedel" sorusunun gündeme geldiği görülmektedir. Genellikle eğer bir etik kurul "normal, sağlıklı gönüllü" için önerilen bedelin çok fazla ya da az olduğunu düşünüyorsa, sorun çıkmaktadır. ABD'de bazı IRB'ler, gönüllülerin katıımları karşıığında minimal bir tazminat almalarını garanti edecek kılavuzlar geliştirmişler, bazıları da gönüllülerin bir beyin grafisi (EEG) incelemesi ya da venöz kan alımı veya arterial kan gazı alımı karşılığında ne kadar bedel alacaklarını belirleyen listeler hazırlamışlardır. Söz konusu uygulamaların ne kadar yaygın ve ortak olduğunu gösteren bilgilere sahip olmadığımız gibi, etik kurulların genel olarak araştırma gönüllülerinin hakları ile (hangi uygulamalara katılacaklarına karar verme hakkı da dahil olmak üzere) zorlama konusundaki kendi bireysel duyguları arasındaki çekişmeyi nasıl çözümlediklerini de bilemiyoruz [9].

Ülkemizde klinik araştırma dünyasında hiç konuşulmayan bir başka konu da, hastaların, kendilerini çalışmaya dahil eden hekimlere ödenen teşvikler konusunda bilgilerinin olmaması konusudur. Hasta bilgilenmek istese de istemese de, araştırmacıya katılım karşılığında teşvikler verilmesinin oldukça düşündürücü olduğu açıktır. Genellikle, hatta sık sık araştırmacılar hastaları araştırmalarına katmakta zorlanırlar. Bu tür katıımı artırmak için hastanede çalışan ve gönüllü hastayı öneren öteki hekimlere de çeşitli teşvikler sunulmaktadır. Katııımcı bulanlara ücret ödeme uygulaması uzun süredir devam eden ve kimilerine göre de yararlı bir uygulamadır. Ancak bu uygulamayı etik dışı bulan, yasalara uygun olmadığını söyleyen, tümüyle yasaklayan kişiler ve kurumlar da bulunmaktadır; buna karşın bu tür uygulamaların klinik ilaç araştırmalarında yaygın olduğu görülmektedir. Ancak bu durumdan hastaların bilgisi yoktur.

$\mathrm{Bu}$ araştırma fonlarının, ödemeden yararlanmak için, standart tedavilerden daha az yararlı ya da intiyaç duyulmayan tedaviler önerme çabasına girişen araştırmacılar için çıkar çatışmaları yarattığını görmek ve bunu beyan etmek gerekir. Bu ödemelerin bir tıp fakültesi dekanı tarafından denetlenen ve daha sonra da tüm fakülte üyeleri tarafından onaylanan araştırma fonu için kullanılacak ortak bir havuzda toplanması uygulaması da bu konuda şimdilik en uygun çözüm olarak sunulmaktadır. 


\section{Sonuç ve Değerlendirme}

Ülkemiz klinik araştırmaların yürütülmesi bakımından görünür avantajlara sahiptir; 80 milyona yaklaşan nüfusu, farklı etnisiteleri barındırması, mevcut hastalık yükü, akraba evliliklerine bağlı genetik hastalıkların görülme sıklığı, nadir görülen hastalıklar açısından avantajlı durumu, genetik benzerlik, benzer morbidite, ICD kodlaması (International Statistical Classification of Diseases and Related Health Problems) ve hastalık yükü araştırmaları ile hastalık çeşitliliğinin bilinmesi ... gibi

Nadir hastalıkların her ülke özelinde etkilediği popülasyon göz önüne alındığında, tedavisi ile ilgili olarak üretilmesi gereken yetim ilaçların araştırma/geliştirme ve pazarlama sürecinde, devletlerin geliştirdiği politikalar önemlidir. Ülkemizde Klinik Araştırmalar Hakkında Yönetmelik'te ifadesini bulduğu gibi, tedavisi henüz yeterince bilinmeyen ve üzerinde klinik araştırma yapılması elzem olan hastalıklar (rare disease) ile bu hastalıklara özel üretilecek yetim ilaç (orphan drug) araştırmaları için, başvurunun doğrudan Sağlık Bakanlığına yapılması gerekmektedir. Illaç endüstrisinin normal piyasa koşullarında hasta sayısının az olması nedeniyle yetim tıbbi ürünlere karşı ilgisi çok azdır. Bu sebeple Avrupa Birliği, ilaç firmalarına araştırmageliştirme için teşvikler sağlamaktadır.

Klinik ilaç ve tıbbi cihaz çalışmalarında mali konular önemlidir ve geçtiğimiz onyıllarda, bir dizi etken klinik ilaç araştırmasının yürütülmesinde mali konuların giderek artan önemine gerekçe olarak gösterilmektedir. Bunun yanı sıra kuşkusuz araştırmacı hekim sayısındaki artış, tıp fakültelerinin gelişmesine bağlı olarak bu hekimlerin araştırmacı niteliklerindeki artış da önemlidir. Genç hekimler için yaygınlaştırılmış araştırma metodolojisi ve araştıma etiği eğitimi programlarında da artı̧̧ olmuştur. Birçok bilim insanının ve hekimin endüstride çalışma konusundaki tutumlarında da değişiklik olmuştur. lyi yetişmiş, nitelikli pek çok hekim, biyoteknoloji şirketleri ve ilaç şirketleri için çalıştıkları akademik kuruluşları terk etmişlerdir. Klinik araştırmalar, hastaları tıp merkezlerine, üniversitelere çekmekte bir araç konumuna da gelmiştir. Belli başlı büyük merkezlerde, özellikle kanser ilaçlarını deneyen tıbbi onkologlar hastalarının büyük bir kısmını klinik araştırma protokollerine dahil etmişler ve böylece araştırmayı standart tıbbi bakımlarının bütünleşik bir parçası yapmışlardır. Bu da, klinik araştırmayı yalnızca hastaları için değil, öğrenciler, hastane hekimleri ve öteki hekimler için rutinleştirmiş ve ilaç üreticilerini klinik deneyleri desteklemelerinde büyük oranda teşvik etmiştir.

Klinik araştırmacı için (temel laboratuar araştırmacısından farklı olarak) hükümet fonlarına ulaşmak daha da güçleşmiş ve klinik araştırmalar, ilaç ve tıbbi alet üreticilerine ve sigorta şirketlerine daha da bağımlı duruma gelmiştir. Türkiye'de klinik araştırmaların (clinical trial) destekleyicilerine baktığımızda beklendiği gibi ilk sırada endüstrinin yer aldığını görürüz. İlaç ve tıbbi cihaz geliştirme çalışmaları endüstri destekli olarak yürütülürken, bu çalışmaların uluslararası ve çok merkezli çalışmalar olduğu da görülmektedir.

Ticari nitelikteki ilaç ve tıbbi cihaz geliştirme araştırmalarının dışında bir de ticari olmayan klinik araştırmalar bulunmaktadır ki bu araştırmaların destekleyicisi ve araştırmacıları sektörün katılımı olmaksızın araştırmaları yürütürler. Girişimsel olmayan klinik araştırmalar (non interventional), nadir görülen hastalıkların tedavilerine dönük çalışmalar (yetim ilaçların üretimi), ilaçların optimal kullanımına yönelik yapılan karşılaştırmalı etkililik araştırmaları, ... bu tür çalışmalardır. Bu tür araştırmalarda destekleyici kamu kurumları (üniversitelerin Bilimsel Araştırma Birimleri- BAB, TÜBITAK) veya araştırmacıların kendileridir- özellikle akademik çalışmalar ve tez çalışmalarında araştırmacıların cepten ödemesi ile- (9)

Teknolojinin ilerlemesi ile Ar-Ge süreçleri desteklenmekte ve yeni teknolojiler yeni ilaç ve tedavilerin geliştirilmesinde rol oynamaktadır. Gelecekte klinik araştırma süreçlerinin bilgisayar destekli sanal metabolizma uygulamaları ile kısalacağı ve klinik deneme oranlarının giderek azalacağı, klinik araştırma sürecinin bazı kısımlarının artık büyük ölçüde sanal ortamda yürütüleceği, bilgisayarlı ilaç tasarımı uygulamalarının yaygınlaşacağı öngörülmektedir. Ayrıca genom uygulamalarının kullanılabilirliği arttıkça kişiselleştirilmiş ilaç uygulamaları da hayata geçirilecektir. Moleküler biyoloji ve biyoteknolojinin evrimi, büyük miktarlarda ilacın, özellikle de proteinlerin seri olarak saf halde üretilmelerine ve böylece kısa bir 
süre içinde daha çok sayıda çalışmanın yürütülmesine yol açmıştır. Biyolojik araştırma tekniklerinin gelişimi; bilim insanlarının, Insan Genomu Projesinde ("Human Genome" Projesinde-HUGO) de görüldüğü gibi moleküler hücresel biyoloji alanlarında daha önce olanaklı olmayan ölçüde araştırmalar yapmalarına neden olmuştur [9].

Klinik araştırmalar alanında günümüzde ve gelecekte tartışmalı alanlardan birisi de, insan kökenli biyolojik örneklerin kullanımı konusu olacaktır. Katılımcılardan alınmış insan kökenli biyolojik örnek ve benzeri maddelerin en yararlı biçimde kullanılmasına gösterilecek özen önemlidir. $\mathrm{Bu}$ bağlamda biyobankaların sorumlulukları da önemlidir. Ülkemizde de bununla ilgili rehberlerin hazırlanma ve uygulanma süreci başlamış olup, HÜ Biyoetik Merkezi (HÜBAM) Araştırma Biyobankacılığı ile ilgili olarak hem araştırmacıların ve hem de etik kurulların kullanabileceği bir Etik Rehber oluşturmuş ve ilgili kişi ve kurumlarla paylaşmıştır [10].

Klinik Araştırmalar dünyasında bilimsel/teknik, etik gereklilikler, hukuki yapılanma, insan gücü ve alt yapl gibi konularda olanaklar, fırsatlar, zayıf yanlar ve geliştirilmesi gereken konular bilinmekte ve çalışımaktadır. İlgili kişi ve kurumların ortak çalışmalarına, ilgili konularda Avrupa Komisyonunun gerekliliklerini sağlayacak yapılanmalara (bilişim teknolojisini de içerecek şekilde) gereksinim vardır, bu çalışmaların ve politikaların "sürdürülebilir" olması çok önemlidir.

\section{REFERENCES}

1. The Convention for the Protection of Human Rights and Dignity of the Human Being with regard to the Application of Biology and Medicine: Convention on Human Rights and Biomedicine (ETS No 164) was opened for signature on 4 April 1997 in Oviedo (Spain).

2. SB İlaç ve Biyolojik Ürünlerin Klinik Araştırmaları Hakkında Yönetmelik $<<$ http://www.saglik.gov.tr/GETAT/belge/138934/ilac-ve-biyolojik-urunlerin-klinikarastirmalari-hakkin-.html >>, erişim tarihi:10.02.2016.

3. SB Tıbbi Cihaz Klinik Araştırmaları Yönetmeliği

4. <<http://www.ttb.org.tr/mevzuat/index.php?option= com content\&view=article\&id=1009:2014-09-0806-30-04\&Itemid=33 $>$, erişim tarihi:10.02.2016.

\section{2001/20/EC Direktifi}

6. $\quad<<$ http://ec.europa.eu/health/human-use/clinicaltrials/directive/index en.htm>>,

$<<$ http://ec.europa.eu/health/files/eudralex/vol1/dir 2001 20/dir 200120 en.pdf>> erişim tarihi:10.02.2016.

\section{2014/536/EC Direktifi}

8. $<<$ http://ec.europa.eu/health/files/eudralex/vol1/re g 2014 536/reg 2014536 en.pdf $\gg$, $\quad$ erişim tarihi:10.02.2016.

9. $<<$ https://www.era-learn.eu/networkinformation/networks/e-rare-3/e-rare-3-jtc-2015>> erişim tarihi:10.02.2016.

10. $<<$ https://clinicaltrials.gov/>> erişim tarihi:10.02.2016.

11. Klinik Araştırmalar Portalı <<http://kap.titck.gov.tr/ >> erişim tarihi:10.02.2016.

12. Büken NÖ "Türkiye'de Klinik Araştırmalar Açısından 2015 yılında Etik / Sağlık Politikaları Bağlamında Neler Yaşandı? Öngörüler Nelerdir?", TBD e.bülten, sayı:23, 2015 $<$ http://www.biyoetik.org.tr/wpcontent/uploads/2015/08/bulten23.pdf >

13. HÜ Biyoetik Merkezi, Araştırma Biyobankacılığı Rehberi

$<<$ http://www.hubam.hacettepe.edu.tr/arsiv/arastir ma bankaciligi.php>> erişim tarihi:10.02.2016. 